\title{
Plasticity of barley in response to plant neighbors in cultivar mixtures
}

\author{
Iris Dahlin (D) - Lars P. Kiær • Göran Bergkvist • \\ Martin Weih • Velemir Ninkovic
}

Received: 7 June 2019/Accepted: 17 December 2019/Published online: 26 December 2019

(C) The Author(s) 2019

\begin{abstract}
Aims Cultivar mixtures can increase productivity through complementarity in resource use, but reported results are often conflicting and the role of plasticity in shaping plant-plant interactions is poorly understood. We aim to determine if individual cultivars show different phenotypic responses when grown in a mixture, whether these responses depend on the neighboring cultivar identity, and how they contribute to variations in productivity and nitrogen $(\mathrm{N})$ use.

Methods Five spring barley cultivars were field-grown in pure stands and in mixtures during 2 years. Plant traits related to development, growth, $\mathrm{N}$ use, and reproduction were measured to identify temporal patterns of plastic responses to neighboring plants.
\end{abstract}

Responsible Editor: Richard J. Simpson.

Electronic supplementary material The online version of this article (https://doi.org/10.1007/s11104-019-04406-1) contains supplementary material, which is available to authorized users.

I. Dahlin $(\bowtie) \cdot$ G. Bergkvist $\cdot$ M. Weih

Department of Crop Production Ecology, Swedish University of Agricultural Sciences, Uppsala, Sweden

e-mail: iris.dahlin@slu.se

\section{P. Kiær}

Department of Plant and Environmental Sciences, University of Copenhagen, Copenhagen, Denmark

\section{Ninkovic}

Department of Ecology, Swedish University of Agricultural Sciences, Uppsala, Sweden
Results Plants in mixtures were shorter and developed slower early in the season, but later on they grew faster and produced more grain than the corresponding pure stands. Some cultivars showed complementary N accumulation only when grown together with specific neighbors. Mechanisms of improved productivity differed between the individual mixtures.

Conclusions Plastic plant-plant interaction between cultivars is an important driver behind the variability in mixing effects. Results contribute to a better understanding of how productivity in cultivar mixtures is affected by plastic adaptation and differentiation of plant traits, depending on the environment created by neighboring genotypes.

Keywords Adaptive plasticity . Biodiversity - Biomass allocation $\cdot \mathrm{N}$ use efficiency $\cdot$ Phenotype

\section{Introduction}

Higher diversity in plant communities can promote productivity and stability, and part of the increased productivity can arise from complementarity in resource use of the community components involved (Loreau and Hector 2001; Zuppinger-Dingley et al. 2014). Further, resource availability and plant neighbors can influence the expression of plant phenotypes, leading to adaptability through plasticity (Schlichting 2002; Van Nuland et al. 2016). Consequently, diversity effects on productivity and stability could be influenced by plastic responses of 
the involved community components, a mechanism which so far is rarely explored.

In agriculture, genotypic diversity can promote vegetative and reproductive yield (Cook-Patton et al. 2011; Reiss and Drinkwater 2018). However, reviews and meta-analyses have revealed substantial variability of this function in crop -stands containing mixtures of genotypes, which do not always show higher productivity than stands containing just one of the mixture's genotypes (Borg et al. 2018; Kiær et al. 2009; Reiss and Drinkwater 2018). Therefore, a better understanding of the processes underlying crop genotypic diversity on productivity is needed in order to (i) explain why some studies find positive effects whereas others do not, and (ii) enable predictive development of sustainable agricultural cropping systems based on genotype diversity.

Productive agriculture usually depends on large amounts of nitrogenous fertilizers, which are expensive and energy consuming, and their use is often associated with great environmental risks (e.g., leaching to groundwater and climate gas emissions) and decreased ecological sustainability in agriculture (Mulvaney et al. 2009). An improvement of nitrogen $(\mathrm{N})$ uptake and use efficiency of crop plants is thus of key importance for maintaining productivity and at the same time improving sustainability in agriculture. Though it is stated in many studies that productivity is improved in cultivar mixtures through complementarity, compensation or facilitation, it has not been examined in detail how $\mathrm{N}$ uptake and use efficiency is affected (e.g. Brooker et al. 2008; Creissen et al. 2013).

Functional traits are morphological, physiological and phenological aspects modulating plant performance via their effects on growth, survival and reproductive output (Violle et al. 2007). Most plant traits are generally considered to be plastic (Schlichting 2002), thereby allowing single genotypes to adapt to local environmental conditions by producing different phenotypes. Trait plasticity has been shown to increase (Cahill and McNickle 2011; Ninkovic et al. 2016; Novoplansky 2016) or decrease (Grenier et al. 2016) individual fitness. In this study, we define plasticity as a genotypedependent characteristic, varying between crop cultivars and different environmental stimuli. In this case, the growth environment was changed through the choice of the neighboring cultivars. Many studies have investigated phenotypic plasticity in response to environmental factors and in response to plant neighbors of other species (reviewed by Gratani 2014). In spite of the altered environments present in cultivar mixtures compared to pure stands (e.g. light regimes in the altered canopies), very little is known about trait plasticity in cultivar mixtures and the extent to which this affects plant growth and development, and in turn cultivar interaction and mixture performance. Essah and Stoskopf (2002) studied mixture performance of barley cultivars with different plant heights. They found a yield advantage compared with pure stands, but not in all combinations. Further, they did not measure if plants responded to mixing with plastic responses of functional plant traits, which could have explained why not all mixtures were more productive in their study. In this study, we assessed a wide range of plant traits of cultivars grown in mixtures and pure stands, covering plant growth, vigor, stretching, development, $\mathrm{N}$ uptake and use efficiency, and reproduction. Yet, understanding plastic responses that allow cultivars to reallocate biomass is fundamentally important for explaining diversity-productivity relationships and significant for designing sustainable and productive cropping systems.

The aim of this study was to determine if a specific cultivar shows different phenotypic responses in functional traits when grown with another cultivar in alternate rows and if this varies dependent on the component cultivars. We hypothesize that

(i) biomass and grain production is promoted by mixtures (overall effect of mixing),

(ii) traits of individual cultivars differ when grown in a mixture as compared to a pure stand (plastic trait response to mixing),

(iii) plastic trait responses depend on the genotypic composition around the focal plant individual (neighborhood effect) and

(iv) traits and properties of two cultivars become more similar when the plants are grown in a mixture (adaptive similarity).

\section{Materials and methods}

To study plastic responses of functional traits in barley (Hordeum vulgare L.), we controlled barley diversity in two consecutive field experiments, in which cultivars were grown in plots of pure stands and in two-cultivar mixtures in alternate rows. This made it possible to 
evaluate individual plant traits at the cultivar level rather than stand level, and assess their interactions with neighboring cultivars. With the idea in mind that phenotypic responses to neighboring plants are dynamic, several plant traits were measured at different occasions to identify developmental plasticity of barley plants in response to plant neighborhood.

\section{Field experiments}

Two field trials were conducted in Central-Eastern Sweden at the Lövsta field research station $\left(59^{\circ} 52^{\prime} \mathrm{N}, 17^{\circ} 48^{\prime}\right.$ E) of the Swedish University of Agricultural Sciences in 2015 and 2016. Soil type at the field site is stiff clay with $50 \%$ clay and $5 \%$ humus content. The topsoil $(0-30 \mathrm{~cm})$ had a $\mathrm{pH}$ of 5.8 with P-Al of $5.6 \mathrm{mg} 100 \mathrm{~g}^{-1}$ and $\mathrm{K}-\mathrm{Al}$ of

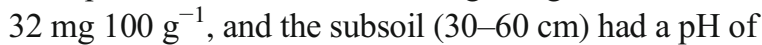
4.7 , with $\mathrm{P}-\mathrm{Al}$ of $2.2 \mathrm{mg} 100 \mathrm{~g}^{-1}$ and $\mathrm{K}-\mathrm{Al}$ of $25 \mathrm{mg}$ $100 \mathrm{~g}^{-1}$ soil (data from 2019). The five spring barley cultivars Salome, Fairytale, Rosalina, Anakin and Luhkas (Table 1) were grown in pure stands and in two-cultivar combinations with a ratio of 50:50. The cultivar Salome was included as a component in all mixtures because it is known to induce plant responses in other cultivars (Dahlin et al. 2018). The fields were sown in the beginning of May with a total number of 400 seeds $\mathrm{m}^{-2}$ and a row spacing of $12.5 \mathrm{~cm}$ without fertilizer applications. We do not usually fertilize our field trials before sowing, because plant-plant interactions can disappear at saturation of plant nutrients. This did not affect the general growth of the plants as the yield of this experimental setting is comparable with 'actual' yields in this region. The experiments were conducted in the same area but with a displacement between the years of about $300 \mathrm{~m}$. Each of the nine treatment plots $(3 \times 9 \mathrm{~m})$ represented a replicate and the plots were placed in a randomized complete block design with six blocks, having a distance of $1 \mathrm{~m}$ between plots. The corridors between the plots were unsown and regularly weeded by hand. Average temperature, precipitation and wind speed were measured by the LantMet weather station located approximately $1 \mathrm{~km}$ from the experiment. The average daily temperature during the growing season (22nd May to 10th September in 2015 and 12th May to 30th August in 2016) was $14.7^{\circ} \mathrm{C}$ in 2015 and $15.2{ }^{\circ} \mathrm{C}$ in 2016 . Precipitation sum during the growing season was $414 \mathrm{~mm}$ in 2015 and $262 \mathrm{~mm}$ in 2016 and the mean wind speed was around $1.5 \mathrm{~m} \mathrm{~s}^{-1}$ in both years.

\section{Acquisition of trait data}

A wide range of plant traits was assessed in each plot, covering plant development, growth and vigor, stretching, $\mathrm{N}$ uptake and use efficiency, and reproduction. To avoid edge effects, no plants were assessed in the outer $0.5 \mathrm{~m}$ of the plots. We used the $\mathrm{BBCH}$ scale in the determination of development stages (Lancashire et al. 1991) to describe the phenological development of the crop, in which $\mathrm{BBCH}$ 0-09 indicate germination, BBCH 10-19 leaf development, BBCH 20-29 tillering, BBCH 30-39 stem elongation, $\mathrm{BBCH} 41-49$ booting, $\mathrm{BBCH}$ 51-59 heading, $\mathrm{BBCH}$ 61-69 flowering, $\mathrm{BBCH} 71-77$ fruit development, $\mathrm{BBCH}$ 83-89 ripening and $\mathrm{BBCH} 92-$ 99 senescence. The number of shoots per plant was estimated along two representative meter transects following the rows in each plot by counting the number of plants before the onset of tillering, the number of shoots during stem elongation and dividing the number of shoots with the number of plants. As a measure of plant development, the growth stage of each of five randomly chosen plants per cultivar per plot was determined 13 July 2015 (52 days after

Table 1 Spring barley cultivars used in this study

\begin{tabular}{|c|c|c|c|c|c|c|}
\hline Cultivar & Breeder & Pedigree & Type & Maturity (d) & Yield index ${ }^{a}$ & Plant height $(\mathrm{cm})^{\mathrm{b}}$ \\
\hline Anakin & Sejet Plant Breeding, DK & Tumbler x Respons & Fodder & 110 & 103 & 70 \\
\hline Fairytale & Sejet Plant Breeding, DK & Colston x (Recept x Power) & Fodder & 110 & 101 & 71 \\
\hline Luhkas & R.A.G.T. Seeds Ltd., UK & Annabell x Prestige & Fodder & 108 & 101 & 68 \\
\hline Rosalina & Sejet Plant Breeding, DK & Beatrix x Eskobar & Malt & 109 & 99 & 68 \\
\hline Salome & Nordsaat Saatzucht GmbH, DE & Auriga x (Publican x Beatrix) & Malt & 109 & 104 & 64 \\
\hline
\end{tabular}

${ }^{a}$ Percentage relative to a reference mixture of cv. Prestige, Justina, Orthega and Gustav

${ }^{\mathrm{b}}$ Multi-year average (Larsson et al. 2013) 
sowing) and 28 June 2016 (47 days after sowing). In addition, the average growth stage across treatments was recorded on the day of all other trait assessments. The leaf chlorophyll content was assessed in five randomly selected plants per cultivar per plot. Three leaves (the first to the third leaf measured downwards) of each plant were measured, using a SPAD502 chlorophyll meter (Konica Minolta sensing inc, Japan). This was done at flowering (BBCH 61) in 2015 and at emergence of the flag leaf (BBCH 40) in 2016. The selected plants were then cut at soil surface, and the three leaves were detached and scanned individually, using a flatbed scanner (EPSON Perfection 4900 3.4, Regent Instruments, Quebec, Canada). Leaf area was then quantified, using Win-RHIZO Pro V 2007 software (Regent Instruments, Quebec, Canada). Those leaves were also weighed, after drying at $70{ }^{\circ} \mathrm{C}$ for $24 \mathrm{~h}$ and the specific leaf area was calculated. Biomass production was assessed by destructive sampling of ten randomly chosen plants per cultivar per plot at three time points: when first tiller was visible (BBCH 21), at early flowering (BBCH $61)$ and at maturity (BBCH 87). Plant material was dried at $70{ }^{\circ} \mathrm{C}$ for $24 \mathrm{~h}$ before measuring the dry weight. The plant height was measured manually from the soil surface to the end of the upper leaf sheath (Pérez-Harguindeguy et al. 2013) on ten randomly chosen plants per cultivar per plot. This was done at advanced tillering $(\mathrm{BBCH} 24$, at this time point it was the leaf length measured), booting $(\mathrm{BBCH} 47)$ and early flowering $(\mathrm{BBCH} 61)$ in 2015 , as well as at jointing $(\mathrm{BBCH} 31)$ and emergence of the flag leaf (BBCH 40) in 2016. The number and height of nodes of these plants were also recorded. $N$ content and grain mass were assessed on plants along the above mentioned transects which were harvested by cutting at soil surface at maturity (BBCH 87). Following oven drying at $70{ }^{\circ} \mathrm{C}$ for $24 \mathrm{~h}$, the green biomass at $\mathrm{BBCH} 21$ and $\mathrm{BBCH} 61$ was ground with a ball mill (MM 400, Retsch, Haan, Germany) and the $\mathrm{N}$ concentrations were analyzed by Near Infrared Transmittance (Infratec ${ }^{\text {TM }} 1241$ Grain Analyser, FOSS, Hillerød, Denmark). Barley heads were threshed, using a stationary research thresher/blower (Siemens-Schuckert, Germany) and estimates of grain mass and $N$ content in the grains were recorded, using the same method for $\mathrm{N}$ content in the grains as for leaf $\mathrm{N}$ content. As plants were harvested along marked transects, where previously no destructive harvests were conducted, the final grain yield and biomass was not impacted by previous assessments. The time points of measurements and samplings differed for the 2 years due to divergent growth rates of plants caused by different weather conditions. Mean values of plant traits are given in Online Resource 1.

\section{Calculations}

To quantify the speed of plant growth, relative growth rate $\left(R G R, d^{-1}\right)$ was calculated as the increase in aboveground biomass per day, using the following equation (Hoffmann and Poorter 2002):

$R G R=\frac{\left(\ln W_{2}-\ln W_{1}\right)}{\left(t_{2}-t_{1}\right)}$

where $W_{1}$ and $W_{2}$ are mean aboveground plant dry weights at times $t_{1}$ and $t_{2}$, respectively. The RGR was also quantified for the growth of plant height, and referred to as relative stretching rate. Late stretching rate was calculated as the increase in the growth of plant height between 52 and 68 days after sowing in 2015.

The specific leaf area (SLA, $\mathrm{m}^{2} \mathrm{~g}^{-1}$ ), used to estimate a component of leaf biomass allocation, was calculated as the leaf area per leaf weight (Vile et al. 2005):

$S L A=\frac{\text { leaf area } \mathrm{m}^{2}}{\text { leaf weight } g}$

The plant $\mathrm{N}$ uptake and use efficiency was assessed using a plant-based approach developed by Weih et al. (2011), with terminology modified by Weih et al. (2018). Accordingly, overall plant $\mathrm{N}$ accumulation efficiency (NAE) is the $\mathrm{N}$ amount in the produced grain per unit $\mathrm{N}$ amount in the sown grains $\left(\mathrm{g} \mathrm{g}^{-1}\right)$, broken down into three components as shown in eq. 3 .

$N A E=U_{N} \cdot E_{N, y} \cdot C_{N, g}$

where the mean $\mathrm{N}$ uptake efficiency $\left(U_{N} ; \mathrm{g} \mathrm{g}^{-1}\right)$ is obtained as the mean $\mathrm{N}$ amount per plant during the growth period per $\mathrm{N}$ amount in the seed grain. The grain-specific $\mathrm{N}$ efficiency $\left(E_{N, y} ; \mathrm{g} \mathrm{g}^{-1}\right)$ is obtained as the biomass of harvested grain divided by the mean $\mathrm{N}$ amount per plant accumulated during the growth period, which reflects the grains produced at final harvest per mean plant $\mathrm{N}$ content (or $\mathrm{N}$ productivity). The grain $\mathrm{N}$ concentration at final harvest $\left(C_{N, g} ; \mathrm{g} \mathrm{g}^{-1}\right)$ is obtained as the $\mathrm{N}$ carry-over from the whole plant to the grains (the 
grain $\mathrm{N}$ allocation divided by the grain biomass allocation at final harvest) (Weih et al. 2011).

Differences in the final dry matter partition (harvest index, HI) were calculated as the ratio of harvested grain biomass to total aboveground biomass (Gifford et al. 1984):

$H I=\frac{\text { grain yield }}{\text { biomass yield }}$

\section{Statistical analysis}

Mixed linear models were employed for most statistical analyses, using the nlme package in $R$ (Pinheiro et al. 2014). With the study focus being plant response rather than crop performance, the genotype-within-plot was set as the experimental unit. Thus, when multiple plants were subsampled within a plot, they were considered as randomly selected representatives of any plant growing in the stand. Field observations and initial statistical tests identified non-linear soil gradients in each field trial, significantly affecting most traits measured. These gradients in plant growth (over a range of characteristics) were identified in both years, possibly being soil legacy effects. Spatial variability can be identified in many field trials. While a proportion of this variability is typically accounted for by the pre-hoc experimental design and subsequent statistical analysis as inter-block variability (as was also done in this study), substantial spatial variability may still remain unaccounted for, which may lead to erroneous conclusions (Singh et al. 2003). Once identified, such soil gradients can be incorporated in a quantitative manner in post-hoc spatial modeling, which is a useful way to account for more of the actual variation in growth conditions and thus increasing the accuracy of estimated genetic effects whether or not being attributed to particular soil factors (Hu and Spilke 2009). In 2015, the soil gradient followed a third order polynomial, whereas in 2016, the gradient followed a second order polynomial. For this reason, year-specific analyses were conducted for each trait, including position variables in models of the general form

trait value $\sim \mathrm{X}+\mathrm{c} 1+\mathrm{c} 2+\mathrm{c} 3+($ gtplot $)+\varepsilon$

where $\mathrm{c} 1, \mathrm{c} 2$ and $\mathrm{c} 3$ denote first, second and third polynomial orders of position in the field (c3 used in 2015 only), gtplot denotes the random effect of 'individuals of each genotype in a plot', and $\varepsilon$ denotes the residual error. The main term $\mathrm{X}$ varied among models, depending on the plastic response to mixing being tested. For each plant functional trait, overall response to mixing was evaluated by setting diversity level as the main factor, thus testing for differences in trait values of plants (of any genotype) grown in mixtures and pure stands, respectively (i.e. plastic response to mixing). Cultivar differences in plastic response to mixing were evaluated by using cultivar, diversity level and their interaction as three main factors and testing for an interaction effect. The effect of cultivar pair (mixture) on plastic response was evaluated by using mixture identity, diversity level and their interaction as three main factors and testing for an interaction effect. Neighborhood effect was evaluated by testing for this interaction effect on Salome only, being grown in mixture with each of the other four cultivars (adaptive similarity).

We tested whether the measured traits of cultivars became more similar when they grew together in a mixture, as compared to each one growing in a pure stand. As a measure of such adaptive similarity, we calculated the absolute difference in trait values of two cultivars. This was done using pure stand (" $\Delta$ pure') and mixture values (' $\Delta$ mix'), respectively. For each trait and for the overall average, the 'deltas' in pure stands and mixtures were compared, using one-way ANOVA.

Overall plastic responses across multiple trait variables were evaluated, using the permutational multivariate analysis of variance through distance matrices included in the vegan package in $\mathrm{R}$ (Oksanen et al. 2018). This allows for differences in direction and intensity of trait responses to mixing, through the use of pairwise (Euclidean) distances rather than the original trait values. Analyses were made for all traits combined (full dataset) and for each of a number of trait groups, comprising traits related to height/stretching (plant height, number of internodes, internode height and height per biomass), growth and vigor (number of shoots, leaf area, SLA, SPAD and biomass), $\mathrm{N}$ uptake and use (leaf $\mathrm{N}$ content, grain $\mathrm{N}$ concentrations, $\mathrm{N}$ uptake efficiency, yieldspecific $\mathrm{N}$ efficiency and NAE) and reproduction/yield (grain mass and harvest index), respectively. For each trait group, we tested for general effects of mixing, cultivar genotype, and their interaction. Test results from the full model were reported when the interaction was significant, or else the results from the model with main terms only. 
Prior to all analyses, normality and homoscedasticity were determined for each trait by plotting the observed values against their residuals, and third-root or natural logarithm transformations were used to normalize variables with skewed distribution. Each trait was analyzed at each measured time point (trial year and days after sowing).

\section{Results}

Overall effect of mixing

Mixing generally promoted final biomass and grain production of cultivars (but not significantly in 2015; Table 2). Cultivar mixtures had lower $H I$ and $N$ concentrations in the leaves in 2015, and produced more biomass in 2016, reaching heavier grain mass compared with pure stands. Plants in mixtures developed more slowly in both years and were shorter relative to pure stands early in the season (Fig. 1a, b and d). However, they had a more rapid relative stretching rate later in the growing season, ultimately reaching approximately the same height as plants in pure stands (Fig. 1c, e). The $N$ uptake and use efficiency traits of mixtures and pure stands were not significantly different in any year, and the same was true for all leaf traits.

Plastic responses to mixing

Compared to the cultivars grown in pure stands, each of the five cultivars exhibited different trait responses when grown in mixtures in 2015 (Table 3). Salome responded to mixing with a slower development of growth stages. The most pronounced difference in plant development between cultivars in mixtures and pure stands was found for Salome, which, at the same time, was at BBCH 31 when grown together with Anakin, at $\mathrm{BBCH} 32$ when grown together with Fairytale and Luhkas, and BBCH 41 when grown with Rosalina, while Salome grown in pure stands was already at $\mathrm{BBCH}$ 49. Fairytale and Anakin responded to mixing with shorter plant heights early in the season. Later in the season, Salome, Fairytale and Luhkas responded to mixing with a faster relative stretching rate. Anakin and Salome responded with lower grain mass relative to biomass (harvest index, HI).

Mixture-specific trait responses were observed in 2015 (Table 4). Salome developed slower when grown with Anakin than when grown alone (evaluated as $\mathrm{BBCH}$ at 13 July). Salome grown together with Rosalina had a higher relative growth rate, $R G R$ (between 24 and 110 days after sowing) and a higher final biomass production (Table 4). Fairytale responded to mixing by exhibiting a shorter plant height and higher late stretching rate. Anakin responded with a shorter plant height and a lower $H I$ when grown together with Salome. In 2016, no mixture-specific cultivar responses were found, although all pair-wise mixtures varied significantly from one another.

Neighborhood effects

Plastic responses depended on the neighborhood of the focal plants. This response was seen in the number of shoots, RGR, specific leaf area (SLA), biomass, grain mass, and $\mathrm{N}$ accumulation efficiency (NAE) in 2015 (Table 5). For example, Salome had a higher NAE and vegetative biomass when grown with Rosalina than when growing with either of Fairytale, Anakin or Luhkas and produced more grain mass than when grown with Fairytale and Anakin (Fig. 2) in 2015. Finally, Salome had a more rapid relative stretching rate (between 40 and 52 days after sowing) when grown with Luhkas than when grown with Fairytale. In 2016, no neighbor effects were observed, except for Salome, which exhibited a higher chlorophyll content in the first upper leaf when grown with Rosalina than when grown with Anakin.

\section{Adaptive similarity}

Plants grown in mixtures generally exhibited greater similarity in resource acquisition traits than plants grown in pure stands (Table 6). For Salome and Luhkas mixed, such adaptive similarity was marked for plant height and relative stretching rate in 2015. Salome and Anakin were more similar in early relative stretching rate and $N A E$ when they grew together in a mixture. In 2016, Salome and Anakin had a high adaptive similarity of $N$ content in their grains and yield-specific $N$ efficien$c y$ (Table 6). No adaptive similarity effects were found in the Salome-Fairytale and Salome-Rosalina mixtures. The overall trait difference in 2015 was smallest for the mixture Salome-Rosalina $(\Delta \mathrm{pure} / \Delta \mathrm{mix}=0.6)$ - indicating that they became most similar compared to growth in their respective pure stands, whereas Salome-Luhkas mixtures had the highest overall trait differences $(\Delta$ 
Table 2 Tests of the overall effect of mixing on plant functional traits, i.e. the plastic change of spring barley plants in response to growing in a mixture, and the proportional change (prop) as the percentage change from performance in pure stands

\begin{tabular}{|c|c|c|c|c|c|c|}
\hline \multirow[b]{2}{*}{ Plant trait } & \multicolumn{3}{|c|}{2015} & \multicolumn{3}{|c|}{2016} \\
\hline & $d f$ & $\mathrm{~F}$ & Change (\%) & $d f$ & $\mathrm{~F}$ & Change (\%) \\
\hline Growth stage $\$$ & 72 & $14.1^{* * * *}$ & -6.9 & 76 & $30.9 * * *$ & -3.0 \\
\hline No. of shoots ${ }^{\ddagger}$ plant $^{-1}$ & 71 & 0.1 & -0.8 & 73 & 1.7 & 3.7 \\
\hline $\mathrm{RGR}^{\dagger \epsilon} \mathrm{d}^{-1}$ & 74 & 2.8 & 4.0 & 75 & 2.2 & 3.5 \\
\hline SLA\# $\mathrm{cm}^{2} \mathrm{~g}^{-1}$ & 71 & 0.04 & 1.0 & - & - & - \\
\hline SPAD flag leaf ${ }^{\#}$ leaf $^{-1}$ & 71 & 0.001 & 0.3 & 75 & 0.007 & 0.2 \\
\hline SPAD 2nd leaf ${ }^{\#}$ leaf $^{-1}$ & 71 & 1.2 & 2.9 & 75 & 0.8 & 1.7 \\
\hline Biomass $^{\dagger} \mathrm{g} \mathrm{plant}^{-1}$ & 71 & 2.6 & -10.6 & 75 & 1.0 & 6.4 \\
\hline Biomass $^{\#} \mathrm{~g}_{\text {plant }}{ }^{-1}$ & 71 & 0.001 & 2.9 & 75 & 2.0 & 2.6 \\
\hline Biomass $^{\epsilon}$ g plant $^{-1}$ & 71 & 0.5 & 12.5 & 73 & $9.5 * *$ & 14.7 \\
\hline Height"! cm & 72 & $22.9 * * * *$ & -31.6 & 75 & $13.1 * * *$ & -11.1 \\
\hline Height $^{\$} \mathrm{~cm}$ & 72 & $27.5^{* * * *}$ & -24.5 & 73 & 0.2 & -0.7 \\
\hline Height ${ }^{\#} \mathrm{~cm}$ & 71 & 3.3 & -2.8 & - & - & - \\
\hline Fourth internode ${ }^{\#} \mathrm{~cm}$ & 72 & $6.8^{*}$ & -23.3 & 70 & 0.5 & -5.7 \\
\hline Stretching rate ${ }^{! ! \$} d^{-1}$ & 72 & 0.1 & -0.7 & 75 & $15.4 * * *$ & 14.5 \\
\hline Stretching rate!"\# $\mathrm{d}^{-1}$ & 72 & $21.4^{* * * *}$ & 11.3 & - & - & - \\
\hline Stretching rate ${ }^{\$ \#} \mathrm{~d}^{-1}$ & 74 & 33.0 $* * * *$ & 97.1 & - & - & - \\
\hline $\mathrm{N}$ conc. leaves ${ }^{\dagger} \mathrm{g}_{\text {plant }}{ }^{-1}$ & 72 & $5.1^{*}$ & -21.6 & 71 & 0.7 & -9.6 \\
\hline $\mathrm{N}$ conc. leaves ${ }^{\#}$ g plant $^{-1}$ & 71 & 1.1 & 57.4 & 71 & 0.3 & 0.6 \\
\hline $\mathrm{N}$ conc. grains ${ }^{\epsilon} \mathrm{g}_{\text {plant }}{ }^{-1}$ & 71 & 1.5 & -3.2 & 75 & 0.4 & -4.2 \\
\hline $\mathrm{N}$ acc eff $(\mathrm{NAE})^{\epsilon}$ & 71 & 0.2 & 1.4 & 71 & 0.1 & 5.9 \\
\hline $\mathrm{N}$ uptake eff $\left(\mathrm{U}_{\mathrm{N}}\right)^{€}$ & 71 & 0.7 & 37.4 & 71 & 0.1 & 1.9 \\
\hline Yield-specific $N$ eff $\left(E_{N}, Y\right){ }^{€}$ & 72 & 1.1 & -6.2 & 71 & 0.03 & -2.5 \\
\hline Harvest index ${ }^{€}$ & 74 & $10.3^{* * *}$ & -5.0 & 75 & 2.3 & -2.6 \\
\hline Grain mass $^{€}$ g plant $^{-1}$ & 71 & 0.05 & 3.0 & 73 & $7.5^{* *}$ & 10.6 \\
\hline
\end{tabular}

${ }^{\dagger} 24$ days after sowing (das); ${ }^{*} 38$ das; "' 40 das; ${ }^{\$} 52$ das; ${ }^{\#} 68$ das; ${ }^{€} 110$ das. $* P<0.05 ; * * P<0.01 ; * * * P<0.001$

pure/ $\Delta \operatorname{mix}=2.2)$. In 2016, the highest adaptive similarity was found for Salome-Luhkas (0.3) followed by Salome-Rosalina and Salome-Anakin (both 1.8) and Salome-Fairytale (2.2).

\section{Plastic responses of trait groups}

The effect of growing in a mixture was significant for groups of traits related to height in 2015 and reproductive biomass in 2016 (Table 7). In 2015, plastic responses of cultivars were found for groups of traits related to plant height, growth, $N$ use, reproductive biomass, and across all traits. In 2016, this was true for the groups of traits related to growth, $N$ use and reproductive biomass. Plastic responses of cultivars grown in a mixture were found for $N$ use traits in
2016. Across both years, plastic responses of cultivars were found for groups of traits related to $N$ use and reproductive biomass.

\section{Discussion}

Plastic responses to mixing

We hypothesized that traits of individual cultivars tend to differ when plants are grown in a cultivar mixture as compared to a pure stand. We found that mixtures of barley cultivars developed slower early in the season relative to cultivars in pure stands. If plants in mixtures stay longer in the juvenile vegetative phase, they have more time for leaf- and spikelet primordia growth, 


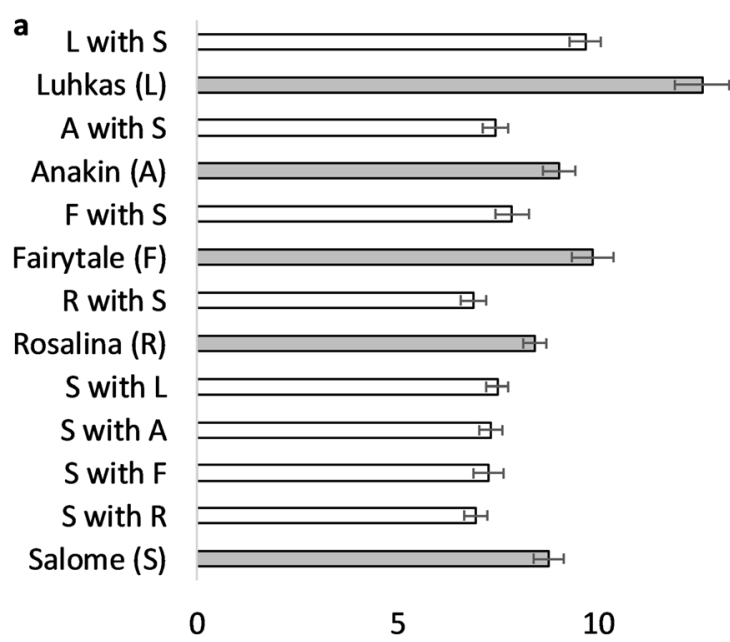

b
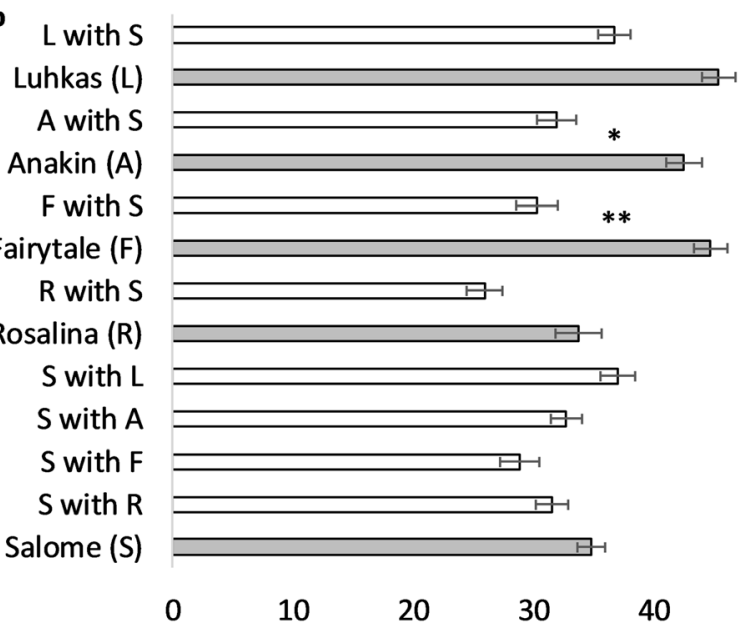

C

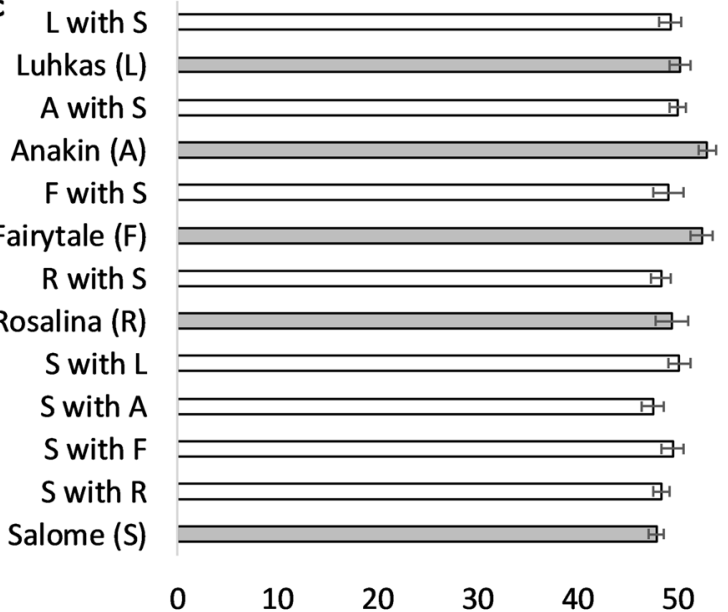

Fig. 1 Plant height $(\mathrm{cm})$ of cultivars grown in mixtures in all tested combinations (white bars) and in pure stands (grey bars), measured 40 (a), 52 (b) and 68 (c) days after sowing in 2015 and

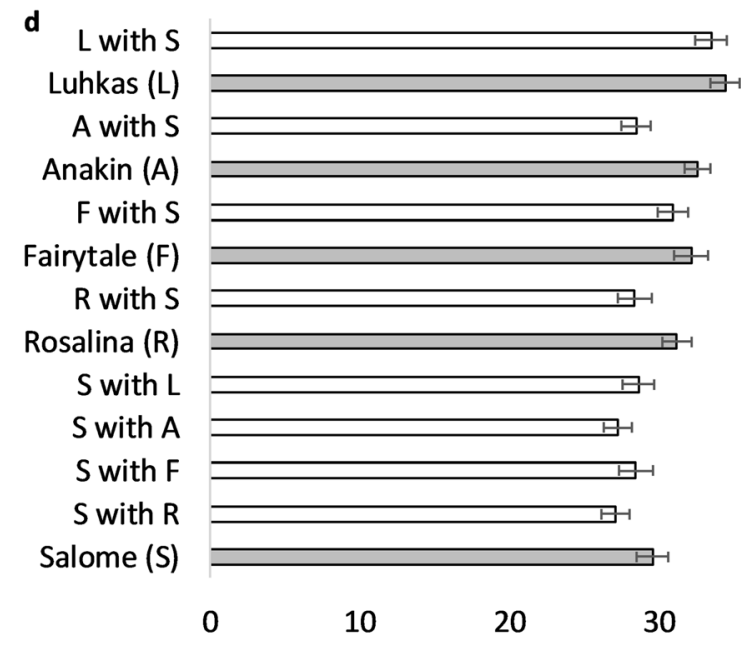

e L with $\mathrm{S}$ Luhkas (L) A with $S$ Anakin (A) F with $S$ Fairytale (F) $R$ with $S$ Rosalina (R)

$S$ with $L$

$S$ with $A$

$S$ with $F$

$S$ with $R$ Salome (S)

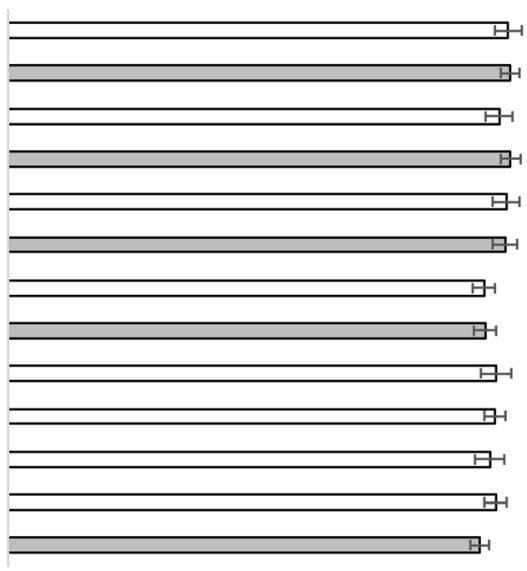

$\begin{array}{llllll}0 & 10 & 20 & 30 & 40 & 50\end{array}$

47 (d) and 57 (e) days after sowing in 2016. Error bars indicate the sample standard errors and asterisks the significance of difference (* $P<0.05 ; * * P<0.01$ ) 
Table 3 To test for a general plastic response to mixing, we evaluated changes in the functional traits of each cultivar when grown in pairwise cultivar mixtures (with Salome evaluated across four mixtures with each of Anakin, Fairytale, Luhkas and Rosalina), as compared to their pure stands. Only significant trait responses are shown. For each plant trait, overall plastic response to mixing was evaluated by setting diversity level as the main factor, testing for differences in trait values between a genotype grown in mixtures and in pure stand (estimates are shown in the columns under each cultivar)

\begin{tabular}{|c|c|c|c|c|c|c|c|}
\hline Plant trait & $d f$ & $\mathrm{~F}$ & Anakin & Fairytale & Luhkas & Rosalina & Salome \\
\hline \multicolumn{8}{|l|}{2015} \\
\hline Growth stage ${ }^{\$}$ & 64 & 0.7 & -2.1 & -2.0 & -2.7 & -1.3 & $-5.4^{*}$ \\
\hline Height ${ }^{\$} \mathrm{~cm}$ & 64 & 1.4 & $-0.4^{*}$ & $-0.5^{* *}$ & -0.2 & -0.3 & -0.1 \\
\hline Fourth internode ${ }^{\#} \mathrm{~cm}$ & 64 & 2.5 & $-1.9 * *$ & -0.3 & 0.2 & -0.9 & 0.004 \\
\hline Stretching rate ${ }^{! ! \#} \mathrm{~d}^{-1}$ & 64 & 0.3 & 0.005 & 0.004 & 0.008 & 0.006 & $0.008 *$ \\
\hline Stretching rate ${ }^{\$ \#} \mathrm{~d}^{-1}$ & 66 & 2.1 & 0.07 & $0.1 * * *$ & $0.09 * *$ & 0.06 & 0.02 \\
\hline Harvest index ${ }^{€}$ & 66 & 0.3 & $-0.04 *$ & -0.03 & -0.02 & -0.02 & $-0.03 *$ \\
\hline
\end{tabular}

"! 40 days after sowing (das); ${ }^{\$} 52$ das; ${ }^{*} 68$ das; ${ }^{€} 110$ das. $P<0.05 ; * * P<0.01 ; * * * P<0.001$

which might partly explain the increased productivity often seen in mixtures. The transition from the vegetative to the reproductive phase is regulated in part by environmental cues (Bäurle and Dean 2006). The altered environment in mixtures in terms of canopy structure could be one reason for a delayed transition. Plants grown in mixtures had a faster relative stretching rate later in the season relative to pure stands, reaching the same final height as plants in pure stand. In fact, height was the most plastic trait in these experiments, and significant changes in plant height were observed already at tillering. Luhkas, a fast-growing cultivar, was $23 \%$ shorter in the beginning of the season when grown with Salome than when grown in pure stands. This suggests a greater competition for light in the pure stand of Luhkas. In contrast, together with the shorter neighbor Salome, Luhkas did not have a strong competitor for light and did not need to invest in elongation. This proposed shade avoidance mechanism suggests that the short Salome would grow taller when grown with Luhkas in order to reach light, but instead, Salome grown with Luhkas was initially $14 \%$ shorter than a pure stand of Salome alone, and later increased its relative stretching rate to reach the same height as Luhkas by the time of the last measurement. The results suggest that plants in cultivar mixtures invest less in shoots early in the season, possibly because they invest more into roots during this period to get sufficient resources for later accelerated growth in size. Previous reports showed that plant early response to the presence of neighboring plants can result in altered biomass allocation to roots (Falik et al. 2006; Ninkovic 2003). Faster establishment of roots into new nutrient patches can facilitate higher nutrient uptake and competitive ability relative to slower, less proliferating cultivars (Rajaniemi 2007); but the relevance of these mechanisms for the specific mixtures compared here needs to be explored in further studies. We found plastic changes in development, plant height and relative stretching rates (especially in the upper section of the stem) affected productivity positively, supporting our first hypothesis. We compared plant growth in mixtures with that in pure stands using a replacement design, which means that any response of plants of a given cultivar is therefore due to the reduced density ("removed") of neighboring individuals of the same cultivar, as much as it is the result of individuals of the other "added" cultivar. This design is a consequence of keeping the seeding rate identical and ensures that any observed changes in plant traits are considered due to changes in the (new) neighbor traits, and not to changes in density.

\section{Neighborhood effects}

We hypothesized that the plastic responses of plants grown in a mixture depend on the genotypic neighborhood. This was tested by comparing the responses of Salome grown with all other cultivars separately. We found that plant traits associated with resource acquisition, growth and fecundity changed in response to neighbor cultivar, including RGR, SLA, grain mass, vegetative biomass, and NAE. Salome, for example, responded with increased NAE when grown with Rosalina, but not when grown with the other cultivars, 
Table 4 Estimates of plastic responses in the functional traits of spring barley cultivars in specific pair-wise mixtures (plants grown with a specific neighbor cultivar) as compared to their respective pure stands (positive estimates indicate higher trait values of respective cultivar in pure stands than when grown with another neighbor). Cultivars are Salome (S), Rosalina (R), Fairytale (F),
Anakin (A) and Luhkas (L); the first letter indicating the cultivar of the focal plant and the second letter indicating the neighbor cultivar ('Salome mixed with Rosalina' etc.). Asterisks after F-values show test results for overall differences between cultivar treatments

\begin{tabular}{|c|c|c|c|c|c|c|c|c|c|c|}
\hline Plant trait & $d f$ & $\mathrm{~F}$ & SR & $\mathrm{SF}$ & SA & SL & RS & FS & $\mathrm{AS}$ & LS \\
\hline \multicolumn{11}{|l|}{2015} \\
\hline Growth stage $\mathrm{e}^{\$}$ & 61 & $2.1^{*}$ & 4.7 & 6.0 & $6.6^{*}$ & 4.2 & 1.3 & 2.0 & 2.1 & 2.6 \\
\hline No. of shoots plant $^{-1}$ & 60 & $3.6^{* * * *}$ & -0.3 & 0.04 & 0.3 & 0.002 & -0.3 & 0.1 & 0.08 & 0.2 \\
\hline $\mathrm{RGR}^{\dagger \epsilon} \mathrm{d}^{-1}$ & 63 & $2.3^{*}$ & $-0.005^{*}$ & -0.002 & -0.001 & -0.001 & -0.003 & 0.001 & -0.002 & 0.001 \\
\hline $\mathrm{SLA}^{\#} \mathrm{~cm}^{2} \mathrm{~g}^{-1}$ & 60 & $2.8^{* *}$ & 2.6 & -8.2 & -7.3 & -11.1 & -10.2 & 17.4 & 3.8 & 6.4 \\
\hline SPAD flag ${ }^{\#}$ leaf $^{-1}$ & 60 & $3.6 * * *$ & -1.2 & 1.6 & 2.3 & -2.0 & 2.1 & 0.2 & -0.2 & 1.0 \\
\hline SPAD 2nd leaf ${ }^{\#}$ leaf $^{-1}$ & 60 & $3.5 * * *$ & -3.5 & -1.3 & -0.3 & -2.0 & -0.5 & -1.3 & 0.3 & 0.7 \\
\hline Biomass $^{€}$ g plant $^{-1}$ & 60 & $3.4 * * *$ & $-0.1 * *$ & -0.009 & 0.04 & -0.01 & -0.1 & 0.01 & -0.03 & 0.04 \\
\hline Height $" !$ cm & 61 & $4.8 * * *$ & 0.2 & 0.1 & 0.2 & 0.1 & 0.1 & 0.1 & 0.2 & 0.2 \\
\hline Height ${ }^{\$} \mathrm{~cm}$ & 61 & $5.8 * * *$ & 0.2 & 0.3 & 0.1 & -0.03 & 0.3 & $0.5^{* *}$ & $0.4^{*}$ & 0.2 \\
\hline Fourth internode ${ }^{\#} \mathrm{~cm}$ & 61 & $2.1^{*}$ & 0.04 & -0.6 & 0.1 & 0.3 & 0.9 & 0.3 & $1 . .9 * *$ & -0.2 \\
\hline Stretching rate!"\$ $\mathrm{d}^{-1}$ & 61 & $2.3^{*}$ & -0.01 & 0.002 & -0.01 & -0.02 & 0.006 & 0.02 & 0.008 & -0.003 \\
\hline Stretching rate!"\# $\mathrm{d}^{-1}$ & 61 & $5.6 * * *$ & $-0.01 *$ & 0.009 & -0.007 & -0.008 & -0.006 & -0.004 & -0.005 & -0.008 \\
\hline Stretching rate ${ }^{\$ \#} \mathrm{~d}^{-1}$ & 63 & $7.2 * * *$ & -0.03 & -0.05 & -0.01 & 0.004 & -0.06 & $-0.1 * * *$ & -0.07 & $-0.09 * *$ \\
\hline $\mathrm{N}$ conc. grains ${ }^{\epsilon} \mathrm{g}_{\text {plant }}{ }^{-1}$ & 60 & $3.2 * *$ & -0.1 & 0.01 & 0.07 & 0.002 & -0.1 & 0.04 & 0.003 & 0.06 \\
\hline $\mathrm{N}$ acc eff $(\mathrm{NAE}){ }^{€}$ & 60 & $3.5 * * *$ & -0.3 & 0.1 & 0.3 & 0.1 & -0.3 & -0.04 & -0.05 & 0.3 \\
\hline $\mathrm{N}$ uptake eff $\left(\mathrm{U}_{\mathrm{N}}\right)^{€}$ & 60 & $2.8 * *$ & -0.3 & -0.1 & 0.06 & -0.08 & -0.2 & -0.09 & -0.08 & 0.1 \\
\hline Harvest index ${ }^{\epsilon}$ & 63 & $5.6 * * *$ & 0.03 & 0.03 & 0.03 & 0.02 & 0.02 & 0.03 & $0.04 *$ & 0.02 \\
\hline Grain mass $^{€} \mathrm{~g}$ plant $^{-1}$ & 60 & $3.2 * *$ & -0.1 & 0.01 & 0.07 & 0.002 & -0.1 & 0.04 & 0.003 & 0.06 \\
\hline \multicolumn{11}{|l|}{2016} \\
\hline SPAD 2nd leaf ${ }^{\#}$ leaf $^{-1}$ & 64 & $2.0 *$ & -1.8 & 0.2 & 1.5 & 0.5 & 1.1 & -1.0 & -0.7 & -1.1 \\
\hline Biomass $^{\epsilon}$ g plant $^{-1}$ & 62 & $2.1^{*}$ & -0.03 & -0.03 & -0.03 & 0.02 & -0.04 & -0.05 & -0.07 & -0.009 \\
\hline Height" $\mathrm{cm}$ & 64 & $3.9 * * *$ & 0.05 & 0.008 & 0.06 & 0.002 & 0.1 & -0.03 & 0.1 & 0.07 \\
\hline Fourth internode ${ }^{\#} \mathrm{~cm}$ & 59 & $2.2 *$ & 0.007 & -0.3 & -0.6 & -0.7 & -0.008 & 0.4 & 0.1 & 0.3 \\
\hline Stretching rate ${ }^{! ! \$} \mathrm{~d}^{-1}$ & 64 & $2.9 * *$ & -0.009 & -0.005 & -0.009 & -0.005 & -0.01 & -0.001 & -0.01 & -0.004 \\
\hline $\mathrm{N}$ conc. grains ${ }^{\epsilon} \mathrm{g}_{\text {plant }}{ }^{-1}$ & 64 & $2.8 * *$ & -0.1 & 0.1 & 0.2 & -0.04 & 0.1 & 0.05 & -0.2 & -0.05 \\
\hline $\mathrm{N}$ uptake eff $\left(\mathrm{U}_{\mathrm{N}}\right)^{€}$ & 60 & $6.2 * * *$ & -0.1 & -0.06 & 0.02 & -0.02 & -0.2 & -0.04 & 0.08 & 0.004 \\
\hline Yield-specific $N$ eff $\left(\mathrm{E}_{\mathrm{N}, \mathrm{y}}\right)^{€}$ & 60 & $3.4 * * *$ & 0.01 & -0.07 & -0.1 & -0.03 & -0.01 & -0.07 & 0.2 & 0.02 \\
\hline Harvest index ${ }^{€}$ & 64 & $7.8 * * *$ & 0.01 & 0.008 & 0.01 & 0.01 & 0.02 & -0.006 & 0.02 & 0.01 \\
\hline Grain mass $^{€}$ g plant $^{-1}$ & 62 & $2.0 *$ & -0.02 & -0.02 & -0.03 & 0.03 & -0.03 & -0.06 & -0.06 & -0.001 \\
\hline
\end{tabular}

${ }^{\dagger} 24$ days after sowing (das); ${ }^{\star} 38$ das; $"{ }^{4} 40$ das; ${ }^{\$} 52$ das; ${ }^{\#} 68$ das; ${ }^{€} 110$ das. $* P<0.05 ; * * P<0.01 ; * * * P<0.001$

resulting in significantly higher biomass and grain yield than in any other cultivar combination. If this neighbor response could be predicted from plant performance in pure stands, responses would be additive (Hughes et al. 2008). However, observed per-plant grain- and biomass were $22 \%$ and $27 \%$ higher than their expected values, respectively. Thus, mixing responses of the two components were non-additive. Such ability for plastic change is genetically determined and we showed that plastic response can vary depending upon different plant stimuli (neighbor cultivars). Our results highlight the importance of evaluating the effect of mixing on the performance of individual components in the mixture, rather than simply comparing the end product (yield) between cultivar mixture and pure stand (as for example in Kaut et al. (2009) and in Kiær et al. (2012)). We propose that 
Table 5 Estimates of neighbor effect, i.e. whether plastic response in the functional traits of Salome (S) plants when growing in a mixture (relative to the pure stand) depends on the neighbor genotype (Rosalina (R), Fairytale (F), Anakin (A) respectively Luhkas (L)). Differences in plastic response of Salome were evaluated by using neighbor cultivar, diversity level and their interactions as three main factors and testing for an interaction effect. Asterisks for F-values shows whether the response depended on neighbor overall, and the other columns show pairwise comparisons between neighbor treatments

\begin{tabular}{|c|c|c|c|c|c|c|c|c|}
\hline Plant trait & $d f$ & $\mathrm{~F}$ & SR-SF & SR-SA & SR-SL & SF-SA & SF-SL & SA-SL \\
\hline \multicolumn{9}{|l|}{2015} \\
\hline No. of shoots plant $^{-1}$ & 17 & $4.7 *$ & 0.3 & $0.6^{* *}$ & 0.3 & 0.2 & -0.03 & -0.3 \\
\hline $\mathrm{RGR}^{\dagger \epsilon} \mathrm{d}^{-1}$ & 20 & $3.2 *$ & 0.003 & 0.003 & 0.004 & 0.001 & 0.001 & 0.001 \\
\hline $\mathrm{SLA}^{\#} \mathrm{~cm}^{2} \mathrm{~g}^{-1}$ & 17 & $3.8^{*}$ & -10.4 & -10.3 & -13.8 & 0.04 & -3.5 & -3.5 \\
\hline Biomass $^{\epsilon} \mathrm{g}_{\text {plant }}{ }^{-1}$ & 17 & $6.5^{* * *}$ & $0.1^{*}$ & $0.2 * * *$ & $0.1^{*}$ & 0.06 & 0.003 & -0.05 \\
\hline Stretching rate $\mathrm{e}^{! \$} \mathrm{~d}^{-1}$ & 18 & 2.9 & 0.02 & 0.001 & -0.006 & -0.01 & $-0.02 *$ & -0.007 \\
\hline $\mathrm{N}$ acc eff $(\mathrm{NAE})^{€}$ & 17 & $4.4^{*}$ & $0.5^{*}$ & $0.7 * *$ & $0.5^{*}$ & 0.2 & -0.02 & -0.2 \\
\hline Grain mass $^{€} \mathrm{~g}_{\text {plant }}{ }^{-1}$ & 17 & $5.1^{*}$ & $0.1^{*}$ & $0.2 * *$ & 0.1 & 0.07 & -0.006 & -0.07 \\
\hline \multicolumn{9}{|l|}{2016} \\
\hline SPAD 2nd leaf ${ }^{\#}$ leaf $^{-1}$ & 19 & 3.3 & 1.9 & $3.3^{*}$ & 2.2 & 1.4 & 0.3 & -1.1 \\
\hline
\end{tabular}

${ }^{\dagger} 24$ days after sowing (das); ${ }^{\star} 38$ das; $"$ " 40 das; ${ }^{\$} 52$ das; ${ }^{*} 68$ das; ${ }^{€} 110$ das. $* P<0.05 ; * * P<0.01 ; * * * P<0.001$

optimizing the performance of all component cultivars in a mixture, by increasing beneficial plant-plant interactions and reducing unproductive interactions, is a better way to enhance the mixed crop stand. To be able to find a mechanistic explanation for variation in mixing effects, all community components in a mixture have to be studied, not just the mean of their responses. In our study, we have showed how the individual cultivars in a mixture respond differently to their neighbors as a result of the differences in plant traits that occur at various stages of development. This is the first study showing that the response of one individual cultivar can vary

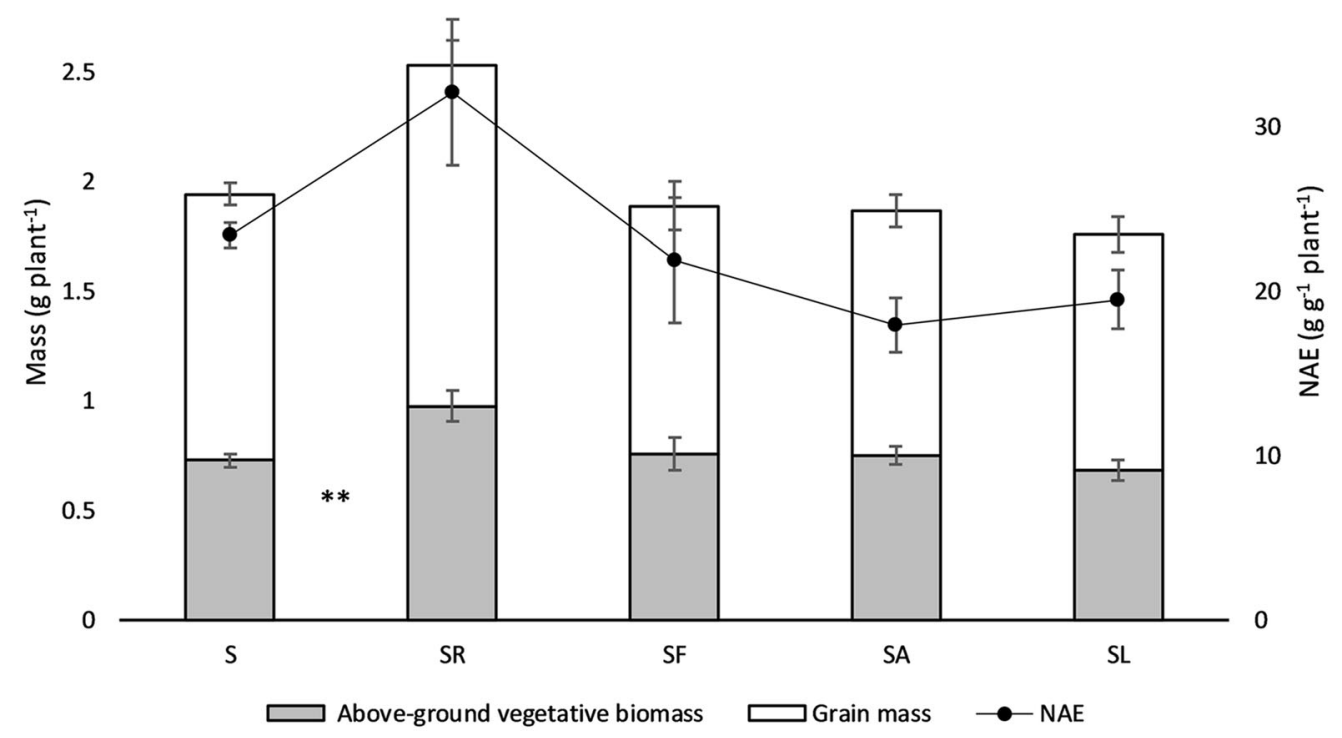

Fig. 2 Biomass (grey bars), grain mass (white bars) and N accumulation efficiency NAE (black line) per plant of cultivar Salome (S) grown in pure stand and together with cultivar Rosalina (R),
Fairytale (F), Anakin (A) or Luhkas (L) in 2015. Error bars indicate the sample standard errors and asterisks the significance of difference $(* P<0.05 ; * * P<0.01)$ 
Table 6 Ratios signifying whether cultivar traits became more similar when they grew in a mixture (' $\Delta$ mix' in combinations of Salome (S), Rosalina (R), Fairytale (F), Anakin (A) and Luhkas (L)), as compared to the trait difference between pure cultures (' $\Delta$ pure')

\begin{tabular}{|c|c|c|c|c|c|c|c|c|}
\hline \multirow[b]{2}{*}{ Plant trait } & \multicolumn{2}{|l|}{ SR } & \multicolumn{2}{|l|}{$\mathrm{SF}$} & \multicolumn{2}{|l|}{ SA } & \multicolumn{2}{|l|}{ SL } \\
\hline & $\Delta$ pure & $\begin{array}{l}\Delta \text { pure } \\
/ \Delta \text { mix }\end{array}$ & $\Delta$ pure & $\begin{array}{l}\Delta \text { pure } \\
/ \Delta \text { mix }\end{array}$ & $\Delta$ pure & $\begin{array}{l}\Delta \text { pure } \\
/ \Delta \text { mix }\end{array}$ & $\Delta$ pure & $\begin{array}{l}\Delta \text { pure } \\
/ \Delta \text { mix }\end{array}$ \\
\hline \multicolumn{9}{|l|}{2015} \\
\hline Height $\$ \mathrm{~cm}$ & 1.0 & 1.1 & 0.92 & 1.1 & 0.94 & 1.1 & 0.91 & $1.1^{*}$ \\
\hline Stretching rate ${ }^{! \$ \$} \mathrm{~d}^{-1}$ & 0.98 & 1.2 & 0.90 & 1.1 & 0.90 & $1.2 *$ & 1.1 & 1,1 \\
\hline Stretching rate ${ }^{\$ \#} \mathrm{~d}^{-1}$ & 0.97 & 0.90 & 1.3 & 0.78 & 1.2 & 0.827 & 1.6 & $0.65^{*}$ \\
\hline $\mathrm{N}$ acc eff $(\mathrm{NAE}){ }^{€}$ & 0.98 & 0.98 & 1.0 & 0.97 & 1.1 & $0.88 *$ & 0.98 & 1.0 \\
\hline \multicolumn{9}{|l|}{2016} \\
\hline $\mathrm{N}$ conc. grains $\mathrm{g}^{\epsilon}$ plant $^{-1}$ & 1.0 & 0.91 & 0.96 & 1.0 & 0.80 & $1.3^{* *}$ & 1.0 & 1.0 \\
\hline Yield-specific $\mathrm{N}$ eff $\left(\mathrm{E}_{\mathrm{N}, \mathrm{y}}\right)^{€}$ & 1.0 & 0.97 & 1.0 & 1.0 & 0.87 & $1.2 *$ & 1.0 & 0.61 \\
\hline
\end{tabular}

"! 40 days after sowing (das); ${ }^{\$} 52$ das; ${ }^{*} 68$ das; ${ }^{€} 110$ das. $* P<0.05 ; * * P<0.01 ; * * * P<0.001$

depending on the other cultivar in the mixture and that this plastic response can significantly influence

Table 7 Plastic responses of combined functional traits assessed in 2015, 2016 and both years combined. For definitions of trait groups, see text (Material and Methods)

\begin{tabular}{|c|c|c|c|c|}
\hline Source of variation & $d f$ & $\begin{array}{l}2015 \\
\text { F-value }\end{array}$ & $\begin{array}{l}2016 \\
\text { F-value }\end{array}$ & $\begin{array}{l}2015 \& 2016 \\
\text { F-value }\end{array}$ \\
\hline & & \multicolumn{3}{|l|}{ All traits } \\
\hline Diversity level & 1 & 0.26 & 0.24 & 0.17 \\
\hline Cultivar & 4 & $4.00 * *$ & 1.64 & 1.40 \\
\hline \multirow[t]{2}{*}{ Diversity level $\times$ Cultivar } & 4 & NS & NS & NS \\
\hline & & \multicolumn{3}{|c|}{ Height/stretching } \\
\hline Diversity level & 1 & $2.75(*)$ & 0.14 & 1.50 \\
\hline Cultivar & 4 & $1.66(*)$ & 1.11 & 1.59 \\
\hline \multirow[t]{2}{*}{ Diversity level $\times$ Cultivar } & 4 & NS & NS & NS \\
\hline & & \multicolumn{3}{|c|}{ Growth and vigor } \\
\hline Diversity level & 1 & 0.20 & 0.25 & 0.10 \\
\hline Cultivar & 4 & $4.07 * *$ & $2.16(*)$ & 1.58 \\
\hline Diversity level $\times$ Cultivar & 4 & $\begin{array}{l}\mathrm{NS} \\
\mathrm{N} \text { use }\end{array}$ & NS & NS \\
\hline Diversity level & 1 & 0.63 & 0.37 & 0.14 \\
\hline Cultivar & 4 & $3.80 * * *$ & $2.77 * *$ & $1.80(*)$ \\
\hline \multirow[t]{2}{*}{ Diversity level $\times$ Cultivar } & 4 & NS & $3.27 * *$ & NS \\
\hline & & \multicolumn{3}{|c|}{ Reproduction/yield } \\
\hline Diversity level & 1 & 0.96 & $4.66^{*}$ & 1.61 \\
\hline Cultivar & 4 & $2.93 *$ & $2.81 *$ & $3.24 * *$ \\
\hline Diversity level $\times$ Cultivar & 4 & NS & NS & NS \\
\hline
\end{tabular}

Significance of difference between cultivar in mixtures and pure stands $((*) 0.05 \leq P<0.10 ; * P<0.05 ; * * P<0.01$; *** $P<0.001)$ are marked in bold productivity in mixtures. This finding can explain the inconsistent effects found in previous studies (e.g. Kiær et al. 2009; Reiss and Drinkwater 2018), and the difficulty of finding general "mixture effects".

\section{Adaptive similarity}

We hypothesized that traits and properties of cultivars become more similar when the plants grow in a mixture. In 2015, we found high adaptive similarity in stretching patterns (plant height and relative stretching rate) in two of the four mixtures. Cultivars Salome and Luhkas, for example, had a high adaptive similarity for plant height. Plants can integrate the genetic identity of neighbors into appropriate adaptive responses by changing their biomass allocation pattern, investing in height growth in order to prevent shading by taller neighbors (Fiorucci and Fankhauser 2017), or in root growth for acquiring more nutrients (Craine and Dybzinski 2013). Grady et al. (2016) found neighbor adaptation of trees and shrubs when comparing individuals neighbored by genotypes from the same and different locations. Plant adaptation to the local environment has evolved through survival of the most adaptive genotypes in the wild. We have shown that this adaptive ability is retained in some cultivars even after hundreds of years of crop breeding. The observed reduction in niche differentiation suggests that the competitive release hypothesized to provide beneficial interactions in plant mixtures may be smaller than anticipated. 
Mixture effects on plastic responses

We hypothesized that plant trait diversity contributes to positive mixture effects on biomass and grain production. We found that the slower development of plants in cultivar mixtures did not affect their productivity. Cultivars grown in pure stands produced similar amounts of grain mass. However, when two cultivars were grown together in a mixture - one of the lowest possible levels of botanical diversity in agricultural fields - they tended to produce more grain and vegetative biomass compared to pure stands (not significant in 2015). It seems that plants in pure stands were associated with faster maturity, and that they had less time for photosynthesis and grain filling compared with plants grown together with another cultivar. This is in line with the nichepartitioning hypothesis, which predicts that competition between close relatives will likely be stronger, due to niche overlap (File et al. 2012). The results suggest that differences among the barley cultivars could result in a different exploitation and utilization of resources (complementarity). Resource limitation is a key mechanism of increased productivity in diverse plant fields (Hooper et al. 2005), which is in line with reports of greater mixture effects in low nutrient environments (Hooper and Vitousek 1997). Increased beneficial results of cultivar mixtures on grain- and vegetative biomass production in harsh environmental conditions were found in other empirical studies (Kiær et al. 2012; Reusch et al. 2005; Tooker et al. 2012) and in a meta-analysis (Reiss and Drinkwater 2018). We want to emphasize, that we used row mixtures and that the effects might be higher in full mixtures.

\section{Plastic responses of combined traits}

Significant differences among cultivars were found in many trait groups in specific years, but few trait groups showed significant response to mixing. Exceptions were height and reproduction traits. The little overlap in the results from the 2 years together indicate a strong dependency on environmental conditions. Plastic responses of the combined grain mass and harvest index between mixtures and pure stands were higher in 2016, suggesting that mixing effect on reproduction is influenced by abiotic conditions. This is in line with plastic responses of cultivars in 2015, 2016 and both years together, which differed in their reproduction traits, suggesting that the cultivars differed in their adaptation to the different weather conditions in these years, which is reflected by their growth and vigor together with their $\mathrm{N}$ uptake and use. The meta-analysis of intraspecific diversity effects on crop yield by Reiss and Drinkwater (2018) revealed stronger diversity effects when exposed to biotic and abiotic stressors. Although annual weather differences in our study were small, we expected greater diversity effects in the cold and wet year 2015 compared to 2016, but no inter-annual differences were observed in our study for diversity effects except for combined reproduction traits. However, mixing effects on single traits, such as growth stage and plant height, were observed across both years. Plant behaviour is influenced by many biotic and abiotic factors and complex interactions between them, which makes them unstable and difficult to predict. Our results provide some evidence for a portion of the diversity effect on productivity to be influenced by plastic responses of the involved community components by means of complementarity in resource use. Realized resource niches seem thus to depend on the identity of the mixture components (here genotypes); and the functional mechanism could be partly related to the trait plasticity of the individual genotypes resulting in different phenotypes. Apart from the implications these findings could have for the design and management of species and cultivar mixtures in agriculture, the results have implications for our understanding of what presently hampers the development of predictive theory regarding the relationship between diversity and productivity in ecosystems.

\section{Conclusion}

This study makes an important contribution to understanding that plastic changes in plant traits are important for the interactions and eventual productivity of cultivar mixtures. The identification of differences in trait plasticity of cultivars grown in different cultivar combinations highlights that these interactions are non-trivial, depending on the identity of the neighbor cultivar. Some cultivars complemented each other through $\mathrm{N}$ accumulation efficiency and yield-specific $\mathrm{N}$ efficiency, which resulted in increased grain and biomass production, while this effect did not occur when they were grown with other cultivar neighbors. The presented findings were based on row mixtures and even stronger plastic responses are expected in full mixtures, which 
are more commonly used. In summary, the results of this study provide a strong indication that trait plasticity might be an important driver of variability seen in experiments testing mixing effects. Intraspecific variation in plastic trait responses may affect niche partitioning and complementarity among barley plants and their performance in multi-cultivar assemblages. Even a small increase in crop diversity could have a large impact on traits important for plant growth and nutrient acquisition, owing to specific properties of the component cultivars. Consequently, traits measured in pure stands may not be sufficient for the tailoring of efficient, stable and predictable cropping systems.

Acknowledgements This work was supported by the Swedish Research Council (project number 2014-225), the Foundation Land Use Research (project number H1333072), and the Danish Agricultural Agency (grant 34009-14-0800). We wish to thank James Ajal, Bara'a Alkhaled, Elin Almström, Ali El Hakeem, Hélène Lamaison, Ewa Magnuski, Dimitrije Markovic and Wilma Pettersson for assistance in the field experiments.

Funding Information Open access funding provided by Swedish University of Agricultural Sciences.

Open Access This article is licensed under a Creative Commons Attribution 4.0 International License, which permits use, sharing, adaptation, distribution and reproduction in any medium or format, as long as you give appropriate credit to the original author(s) and the source, provide a link to the Creative Commons licence, and indicate if changes were made. The images or other third party material in this article are included in the article's Creative Commons licence, unless indicated otherwise in a credit line to the material. If material is not included in the article's Creative Commons licence and your intended use is not permitted by statutory regulation or exceeds the permitted use, you will need to obtain permission directly from the copyright holder. To view a copy of this licence, visit http://creativecommons.org/licenses/by/4.0/.

\section{References}

Bäurle I, Dean C (2006) The timing of developmental transitions in plants. Cell 125:655-664

Borg L, Kiær LP, Lecarpentier C, Goldringer I, Gauffreteau A, Saint-Jean S et al (2018) Unfolding the potential of wheat cultivar mixtures: a meta-analysis perspective and identification of knowledge gaps. Field Crops Res 221:298-313

Brooker RW, Maestre FT, Callaway RM, Lortie CL, Cavieres LA, Kunstler $\mathrm{G}$ et al (2008) Facilitation in plant communities: the past, the present, and the future. J Ecol 96:18-34

Cahill JF, McNickle GG (2011) The behavioral ecology of nutrient foraging by plants. Annu Rev Ecol Evol Syst 42:289-311

Cook-Patton SC, McArt SH, Parachnowitsch AL, Thaler JS, Agrawal AA (2011) A direct comparison of the consequences of plant genotypic and species diversity on communities and ecosystem function. Ecology 92:915-923

Craine JM, Dybzinski R (2013) Mechanisms of plant competition for nutrients, water and light. Funct Ecol 27:833-840

Creissen HE, Jorgensen TH, Brown JKM (2013) Stabilization of yield in plant genotype mixtures through compensation rather than complementation. Ann Bot 112:1439-1447

Dahlin I, Rubene D, Glinwood R, Ninkovic V (2018) Neighborspecific plant-plant communication influences herbivore suppression in cultivar mixtures. Ecol Appl 28:2187-2196

Essah SYC, Stoskopf NC (2002) Mixture performance of phenotypically contrasting barley cultivars. Can J Plant Sci 82:1-6

Falik O, de Kroon H, Novoplansky A (2006) Physiologicallymediated self/non-self root discrimination in Trifolium repens has mixed effects on plant performance. Plant Signal Behav 1:116-121

File AL, Murphy GP, Dudley SA (2012) Fitness consequences of plants growing with siblings: reconciling kin selection, niche partitioning and competitive ability. Proc R Soc Lond B. Biol Sci 279:209-218

Fiorucci AS, Fankhauser C (2017) Plant strategies for enhancing access to sunlight. Curr Biol 27:R931-R940

Gifford RM, Thorne JH, Hitz WD, Giaquinta RT (1984) Crop productivity and photoassimilate partitioning. Science 225 : 801-808

Grady KC, Wood TE, Kolb TE, Hersch-Green E, Shuster SM, Gehring CA et al (2016) Local biotic adaptation of trees and shrubs to plant neighbors. OIKOS 126:583-593

Gratani L (2014) Plant phenotypic plasticity in response to environmental factors. Adv Bot 208747

Grenier S, Barre P, Litrico I (2016) Phenotypic plasticity and selection: nonexclusive mechanisms of adaptation. Scientifica 2016

Hoffmann WA, Poorter H (2002) Avoiding bias in calculations of relative growth rate. Ann Bot 90:37-42

Hooper DU, Vitousek PM (1997) The effects of plant composition and diversity on ecosystem processes. Science 277:13021305

Hooper DU, Chapin FS, Ewel JJ, Hector A, Inchausti P, Lavorel S et al (2005) Effects of biodiversity on ecosystem functioning: a consensus of current knowledge. Ecol Monogr 75:3-35

$\mathrm{Hu}$ X, Spilke J (2009) Comparison of various spatial models for the analysis of cultivar trials. New Zealand J Agr Res 52: 277-287

Hughes AR, Inouye BD, Johnson MTJ, Underwood N, Vellend M (2008) Ecological consequences of genetic diversity. Ecol Lett 11:609-623

Kaut AHEE, Mason HE, Navabi A, O'Donovan JT, Spaner D (2009) Performance and stability of performance of spring wheat variety mixtures in organic and conventional management systems in western Canada. J Agric Sci 147:141-153

Kiær LP, Skovgaard IM, Østergård H (2009) Grain yield increase in cereal variety mixtures: a meta-analysis of field trials. Field Crops Res 114:361-373

Kiær LP, Skovgaard IM, Østergård H (2012) Effects of intervarietal diversity, biotic stresses and environmental productivity on grain yield of spring barley variety mixtures. Euphytica 185:123-138

Lancashire PD, Bleiholder H, Langeluddecke P, Stauss R, van den Boom T, Weber E et al (1991) A uniform decimal code for 
growth stages of crops and weeds. Ann Appl Biol 119:561601

Larsson S, Hagman J, Dryler K (2013) Cereals, legumes, oilsseeds, potatoes, variet selection 2013 [in Swedish]. Institutionen för växtproductionsekologi, SLU, Uppsala.

Loreau M, Hector A (2001) Partitioning selection and complementarity in biodiversity experiments. Nature 412:72-76

Mulvaney RL, Khan SA, Ellsworth TR (2009) Synthetic nitrogen fertilizers deplete soil nitrogen: a global dilemma for sustainable cereal production. J Environ Qual 38:2295-2314

Ninkovic V (2003) Volatile communication between barley plants affects biomass allocation. J Exp Bot 54:1931-1939

Ninkovic V, Markovic D, Dahlin I (2016) Decoding neighbor volatiles in preparation for future competition and implications for tritrophic interactions. Perspect Plant Ecol Evol Syst 23:11-17

Novoplansky A (2016) Future perception in plants. In: Nadin M (ed) Anticipation across disciplines. Springer International Publishing, Cham

Oksanen J, Blanchet G, Friendly M, Kindt R, Legendre P, McGlinn $D$ et al (2018) Vegan: community ecology package. R package version 25-2 https:/CRANR-projectorg/package=vegan. Accessed 7 Jul 2018

Pérez-Harguindeguy N, Diaz S, Garnier E, Lavore S, Poorter H, Jaureguiberry P et al (2013) New handbook for standardized measurement of plant functional traits worldwide. Aust J Bot 61:167-234

Pinheiro J, Bates D, DebRoy S, Sarkar D (2014) R Core Team nlme: Linear and Nonlinear Mixed Effects Models. R Package Version 3.1-117. http://CRAN.R-project. org/package=nlme. Accessed 7 Jul 2018

Rajaniemi TK (2007) Root foraging traits and competitive ability in heterogeneous soils. Oecologia 153:145-152

Reiss ER, Drinkwater RL (2018) Cultivar mixtures: a metaanalysis of the effect of intraspecific diversity on crop yield. Ecol Appl 0:1-16
Reusch TBH, Ehlers A, Hämmerli A, Worm B (2005) Ecosystem recovery after climatic extremes enhanced by genotypic diversity. Proc Natl Acad Sci U S A 102:2826-2831

Schlichting CD (2002) Phenotypic plasticity in plants. Plant Species Biol 17:85-88

Singh M, Malhotra RS, Ceccarelli S, Sarker A, Grando S, Erskine W (2003) Spatial variability models to improve dryland field trials. Exp Agric 39:151-160

Tooker JF, Frank SD, Steffan-Dewenter I (2012) Genotypically diverse cultivar mixtures for insect pest management and increased crop yields. J Appl Ecol 49:974-985

Van Nuland ME, Wooliver RC, Pfenningwerth AA, Read QD, Ware IM, Mueller L, Fordyce JA, Schweitzer JA, Bailey JK (2016) Plant-soil feedbacks: connecting ecosystem ecology and evolution. Funct Ecol 30:1032-1042

Vile D, Garnier E, Shipley B, Laurent G, Navas ML, Roumet C, Lavorel S, Díaz S, Hodgson JG, Lloret F, Midgley GF, Poorter H, Rutherford MC, Wilson PJ, Wright IJ (2005) Specific leaf area and dry matter content estimate thickness in laminar leaves. Ann Bot 96:1129-1136

Violle C, Navas ML, Vile D, Kazakou E, Fortunel C, Hummel I et al (2007) Let the concept of trait be functional! OIKOS 116:882-892

Weih M, Asplund L, Bergkvist G (2011) Assessment of nutrient use in annual and perennial crops: a functional concept for analyzing nitrogen use efficiency. Plant Soil 339:513-520

Weih M, Hamnér K, Pourazari F (2018) Analyzing plant nutrient uptake and utilization efficiencies: comparison between crops and approaches. Plant Soil 430:7-21

Zuppinger-Dingley D, Schmid B, Petersmann JS, Yadav V, De Deyn GB, Flynn DFB (2014) Selection for niche differentiation in plant communities increases biodiversity effects. Nature 515:108-111

Publisher's note Springer Nature remains neutral with regard to jurisdictional claims in published maps and institutional affiliations. 